\title{
STRATEGI GURU DALAM PENGATURAN MEJA KURSI DAN PAJANGAN KARYA SISWA UNTUK MENGOPTIMALKAN PEMBELAJARAN AKTIF KONSEP MIKIR DI SEKOLAH DASAR
}

\author{
Maryono' $^{1}$, Hendra Budiono ${ }^{2}$ \\ ${ }^{1,2}$ Pendidikan Guru Sekolah Dasar, FKIP Universitas Jambi, \\ maryono@unja.ac.id ${ }^{1}$, hendra.budiono@unja.ac.id ${ }^{2}$
}

Received: November 5, 2020 Revised: November 8, 2020

Accepted: November 122020

\begin{abstract}
ABSTRAK
Penelitian ini bertujuan untuk melihat strategi yang digunakan guru khususnya dalam penataan meja kursi dan pemajangan karya siswa dalam upaya mengoptimalkan pembelajaran aktif di Sekolah Dasar. Penelitian ini menggunakan pendekatan kualitatif dengan teknik pengumpulan data diperoleh melalui observasi, wawancara dan dokumentasi. Analisis data menggunakan teknik triagulasi data. Penelitian dilakukan di 6 sekolah dasar Negeri yang merupakan mitra Fakultas Keguruan Universitas Jambi. Hasil penelitian menunjukkan stategi yang digunakan guru dalam penetaan meja kursi meliputi pengaturan meja-kursi disesuaikan dengan tema yang diajarkan, bentuk meja-kursi diganti 1-2 minggu sekali, dan pengaturan meja-kursi disesuaikan dengan bentuk kegiatan pembelajaran (individu, berpasangan, dan berkelompok). Hasil karya siswa dari proses pembelajaran sudah dipajangkan oleh guru di dinding sisi kelas. Berbagai bentuk karya siswa dibuat dengan memilih karya yang cocok untuk dipajang seperti tulisan siswa (cerita, puisi, laporan), dan hasil pembelajaran yang menunjukkan unsur kreativitas
\end{abstract}

Kata Kunci: Pembelajaran aktif, meja kursi, pajangan karya

\begin{abstract}
This study aims to see the strategies used by the teacher, especially in arranging tables and chairs and displaying student work in an effort to optimize active learning in elementary schools. This study used a qualitative approach with data collection
\end{abstract}


techniques obtained through observation, interviews and documentation. Data analysis using data triagulation techniques. The research was conducted in 6 public elementary schools which are partners of the Teaching Faculty of Jambi University. The results show that the strategies used by the teacher in determining the table and chairs include setting the table and chairs according to the theme being taught, the shape of the table and chairs is changed once every 1-2 weeks, and the table-chair arrangement is adjusted to the form of learning activities (individual, pair, and group. ). The students' work from the learning process has been displayed by the teacher on the side wall of the class. Various forms of student work are made by choosing works that are suitable for display such as student writing (stories, poetry, reports), and learning outcomes that show elements of creativity

Keywords: active learning, table and chair, work display

\section{PENDAHULUAN}

Pembelajaran aktif bagian dari impelementasi kurikulum 2013, yang menuntut peserta didik terlibat aktif dalam pembelajaran. Pembelajaran terlaksana baik dalam bentuk fisik maupun dalam bentuk aktivitas non fisik. Hal ini akan terwujud bila suasana yang menyenangkan dapat diciptakan oleh guru, adanya kenyamana dalam proses pembelajaran, pembentukan kedisiplinan, serta adanya prosedur yang menjamin keamanan bagi siswa dlam pelaksanaan pembelajaran

Pada dasarnya pembelajaran aktif sangat diiperlukan dalam proses pembelajaran. Begitu pula pada pembelajaran di sekolah dasar. Di sekolah dasar, bentuk pembelajaran aktif memeungkinkan siswa untuk berperan secara aktif. Hal ini tampak pada kegiatan di kelas contohnya dalam interaksi yang terjadi sesama siswa, maupun siswa dengan guru. Dengan terlaksananya pembelajaran aktif, membuat proses pembelajaran yang bermakna bagi siswa dan memudahkan pencapaian tujuan pembelajaran sebagaimana tuntutan kurikulum yang belaku.

Salah satu konsep pembelajaran aktif yang saat ini banyak digunakan dalam proses pembelajaran dis ekolah dasar adalah konsep pembelajaran aktif MIKiR. MIKiR merupakan akronim dari mengalami, interaksi, komunikasi, dan refleksi. Pendekatan yang berusaha menjawab tantangan abad 21 dan mempraktiskan unsur pendekatan 5M yang ada dalam Kurikulum 2013 dengan tujuan agar pembelajaran dikelas menjadi lebih kreatif, menyenangkan, serta lebih bermakna. Selain itu, setiap 
langkah pendekatan MIKiR mampu memfasilitasi siswa dalam proses pembelajaran di sekolah dasar.

Proses pembelajaran aktif dengan konsep MIKiR akan lebih optimal jika lingkungan belajar siswa tidak membosankan. Sehingga anak terus termotivasi dan suasana belajar akan lebih kondusif. Kelas yang menyenangkan ini tergantung pada bagaimana guru melakukan pengelolaan kelas. Pengelolaan kelas oleh guru merupakan kegiatan yang disengaja agar dapat tercipta kondisi kelas yang optimal dalam proses pembelajaran, selain akan menciptakan proses pembelajaran yang lebih efektif.

Lestari, dkk (2017:61) menjelaskan bahwa guru sebagai seorang pendidik harus mampu menata lingkungan fisik kelas dengan baik. Melalui penataan kelas yang tepat maka akan tercipta suasana belajar yang kondusif, selain itu siswa juga akan mendapat dorongan dan rangsangan untuk lebih semangat dalam mengikuti proses pembelajaran. Penataan lingkungan fisik kelas dapat berupa penataan tempat duduk. Semakin tepat penataan tempat duduk yang dilakukan guru, semakin banyak waktu yang digunakan siswa untuk mengerjakan tugas yang diberikan sehingga siswa berperan aktif dalam proses pembelajaran (Lestari, dkk, 2017:61). Proses pembelajaran dapat berjalan dengan efektif ketika siswa terdorong dan termotivasi untuk belajar. Artinya seseorang melakukan aktivitas belajar karena ada faktor penggerak berupa motivasi (Noviaingsih, 2016:2).

Selain penataan ruang fisik kelas berupa pengaturan meja-kursi, perlu adanya penataan pemajangan karya siswa. Dadi (2016:256) menyatakan bahwa Kelas yang memiliki pajangan atau pameran hasil karya siswa dapat menjadi tempat yang menarik dan dapat memotivasi siswa untuk belajar. Suatu kelas yang kosong tanpa pajangan dapat menjadi tempat yang membosankan, gersang dan tidak menggugah inspirasi siswa.

Universitas Jambi saat ini melakukan kerjasama di berbagai mitra sekolah dasar dibawah naungan Fakultas Keguruan dan Ilmu Pendidikan. Dalam proses pembelajaran di beberapa sekolah dasar yang menjadi mitra Universitas Jambi tampak bahwa guru telah melakukan berbagai stategi dalam pengelolaan kelas 
khususnya pengaturan meja kursi siswa, agar proses pembelajaran aktif dengan konsep MIKiR berjalan dengan optimal. Hal ini memberikan gambaran dan pemahaman bahwa perlu adanya strategi pengaturan meja kursi dan pangan karya siswa dalam upaya mengoptimalkan penerapan pembelajaran aktif dengan konsep MIKiR yang telah dilakukan.

Berdasarkan berbagai hal yang telah diuraikan, peneliti tertarik untuk meneliti Strategi Guru Dalam Pengaturan Meja Kursi dan Pajangan Karya Siswa Untuk Mengoptimalkan Pembelajaran Aktif Konsep MIKIR Di Sekolah Dasar.

\section{METODE}

Penelitian ini merupakan penelitian kualitatif dengan jenis penelitian fenomenologi. Metode ini dipilih karena tujuan penelitian ini adalah untuk meneliti dan mendeskripsikan fenomena yang terjadi pada subjek penelitian secara holistik dalam konteks dan metode yang alamiah (Moleong, 2012: 6).

Pelaksanaan penelitian dilakukan di sekolah mitra LPTK Universitas Jambi

yang terdiri atas 3 sekolah dasar yakni SDN 131/IV Kota Jambi, SDN 76/IX Mendalo, SDN SDN 236/IX Aur Duri. Pemilihan ini didasarkan pada pertimbangan bahwa sekolah ini telah menjalin kerjasama dan telah melaksanakan pembelajaran aktif konsep MIKiR. Penelitian akan dilaksanakan dari bulan Januari sampai dengan September 2020.

Untuk memperoleh data yang diperlukan, maka peneliti dalam penelitian kualitatif ini menggunakan beberapa teknik pengumpulan data yakni observasi, wawancara dan studi dokumentasi. Analisis data menggunakan teknik analisis data yang dikemukakan oleh Miles dan Huberman, meliputi reduksi data, penyajian data, dan penarikan kesimpulan. Uji kebasahan data menggunakan metode triangulasi metode.

\section{HASIL DAN PEMBAHASAN}

Penelitian strategi pengaturan meja kursi dan pemajangan karya siswa untuk mengoptimalkan pembelajaran aktif konsep MIKIR di Sekolah Dasar dilaksanakan di 
6 sekolah dasar yang menjadi mitra Universitas Jambi. Pembelajaran aktif konsep MIKiR merupakan salah satu praktik baik yang telah dilakukan kurang lebih selama 3 tahun, yang dimulai pada awal tahun 2018 sampai dengan tahun 2020. Tindak lanjut dari pelatihan adalah adanya pendampingan oleh dosen kepada guru-guru terdamping disetiap sekolah. Dalah satu yang menjadi fokus pendampingana dalah pengelolaan kelas khususnya dalam pengaturan meja kursi dalam pengoptimalam pembelajaran aktif dengan konsep MIKiR yang telah dilakukan.

\section{Strategi guru dalam Pengaturan meja-kursi siswa}

Pengaturan meja-kursi atau pengelolaan tempat duduk siswa merupakan bagian penting dan menjadi salah satu penentu keberhasilan pembelajaran aktif. Penetaan meja-kursi yang memenuhi kriteria mobilitas, interaksi dan akses (MIA) akan membangun proses pembelajaran yang lebih interaktif, komunikasi lebih produktif, dan siswa dapat lebih mudah melakukan kegiatan pembelajaran. Hasil pengamatan menunjukan bahwa guru mitra LPTK memiliki kemampuan dalam penataan meja-kursi siswa yang memenuhi kriteria MIA. Hal ini terlihat adanya bentuk penataan meja kursi yang bervariasi. Penataan meja-kursi yang dirancang guru dilakukan berubah-ubah yang disesuaikan dengan bentuk kegiatan pembelajaran. Pengaturan meja-kursi dilakukan secara bekala 1-2 minggu sekali. Bentuk-bentuk pengaturan meja-kursi yang dilakukan oleh guru berbagai macam bentuk baik lingkaran, bentuk $\mathrm{U}$, berpasangan, atau berkelompok yang disesuaikan dengan jumlah kelompok. Zaturrahmi (2019:1) menyatakan bahwa lingkungan yang kondusif akan sangat mendukung kenyamanan proses pembelajaran yang dialami oleh siswa. Hal ini akan berdampak pada motivasi belajar dan minta serta pola pikir yang positif bagi siswa, sehingga akan tumbuh kesadaran untuk belajar yang lebih baik. Selain itu, lingkungan belajar yang kondusif juga akan berdampak kepada guru. Guru akan lebih termotivasi untuk mengajar secara optimal, karena merasa nyaman dengan lingkungan belajar. 
Wawancara bersama ibu SM guru kelas 1 SDN 131/IV Kota Jambi menyatakan bahwa:

“dalam proses pembelajaran khususnya di kelas 1, penataan mejakursi sangat membantu terlaksananya proses pembelajaran, anak-anak tidak merasa bosan dengan suasana kelas. Hanya saja untuk kelas 1 pemilihan bentuk pengaturan meja-kursi perlu pertimbangan yang matang, mengingat anak-anak di kelas 1 sangat aktif, tidak bisa diam, yang mengharuskan pengaturan meja-kursi ada jarak antar siswa” Wawancara, Jumat 8 Agustus 2020).

Pengamatan terhadap pengaturan meja-kursi selama proses pembelajaran menunjukan bahwa siswa lebih mudah berinteraksi dan berkomunikasi antar siswa. Penataan meja-kursi yang bervariasi menyebabkan siswa lebih bersemangat tidak bosan mengikuti proses pembelajaran. Isbadrianingtyas, dkk (2016:903) menyetakan bahwa perlu adanya modifikasi tempat duduk dalam proses pembelajaran. modifikasi ini disesuaikan dengan kebutuhan siswa. Beberapa pilihan dalam melakukan modifikasi tempat duduk yaitu dapat menggunakan bangku dan meja maupun tidak. Selain bangku, tempat duduk siswa dapat digantikan denga tikar atau karpet.

Hasil wawancara bersama ibu NE guru kelas 3 SDN 236/IX Aur Duri tentang penataan meja kursi dalam implementasi pembelajaran katif, beliau berpendapat:

"Penataan meja-kursi sangat membantu proses pembelajaran yang lebih kondusif. Siswa tidak bosan dengan kegiatan pembelajaran yang dilakukan. Selian itu dengan adanya penatan meja-kursi yang senantiasa bervariasi membangun komunikasi antar siswa yang lebih interaktif, siswa dapat bekerjasama dengan baik, serta ruang gerak siswa lebih leluasa saat roses pembelajaran berlangsung” (Wawancara Kamis, 13 Agustus 2020).

Berdasarkan hasil penelitian, berbagai bentuk usaha guru dalam pembelajaran aktif dengan penataan meja-kursi sebagai berikut: 
Tabel 1. Bentuk strategi guru dalam penataan meja-kursi

\begin{tabular}{|l|l|}
\hline $\begin{array}{l}\text { Bentuk Implementasi } \\
\text { Pembelajaran Aktif }\end{array}$ & \multicolumn{1}{|c|}{ Strategi yang digunakan guru } \\
\hline Penataan Meja-Kursi & $\begin{array}{l}\text { Pengaturan meja-kursi disesuaikan } \\
\text { dengan tema yang diajarkan }\end{array}$ \\
\cline { 2 - 2 } & $\begin{array}{l}\text { Bentuk meja-kursi diganti 1-2 minggu } \\
\text { sekali }\end{array}$ \\
\cline { 2 - 2 } & $\begin{array}{l}\text { Pengaturan mej-kursi disesuaikan } \\
\text { dengan bentuk kegiatan pembelajaran } \\
\text { (individu, dan } \\
\text { berkelompok) }\end{array}$ \\
\hline
\end{tabular}

\section{Strategi Guru dalam Pemajangan Karya Siswa}

Pemajangan karya merupakan bagian dari implementasi pembelajaran aktif. Pemajangan karya siswa telah dilakukan sebagian besar guru yang mengikuti pelatihan pembelajaran aktif program Pintar Tanoto. Hasil pengamatan selama proses pendampingan menunjukkan bahwa karya siswa hasil dari proses pembelajaran dipajangkan di dinding sisi kelas. Berbagai bentuk karya siswa dibuat dengan memilih karya yang cocok untuk dipajang seperti tulisan siswa (cerita, puisi, laporan), dan hasil pembelajaran yang menunjukkan unsur kreativitas. Wawancara bersama Ibu NH, guru kelas 1 SDN 76/IX Mendalo menyatakan bahwa:

Pemajangan karya siswa yang saya lakukan mengikuti petunjuk yang sudah didapat selama pelatihan program Tanoto Foundation yang berfungsi sebagai Motivasi, Apresiasi, Sumber belajar, Umpan balik, dan Komunikasi (MASUK). Karya siswa yang dipajang biasanya hasil karya siswa yang terbaik misalnya tulisan dalam bentuk puisi, cerita, maupu laporan pengamatan siswa. Selain itu bentuk pajangan lain seperti kolase maupun gambar-gambar hasil kerja siswa juga dipajang disudut dinding kelas. Pajang karya ini selalu diganting seminggu sekali atau disesuaikan dengan kaya-karya siswa yang dihasilkan pada subtema yang dipelajari. (Wawancara Rabu, 5 Agustus 2020).

Berdasarkan hasil penelitian, guru berusaha untuk memajang hasil karya yang dihasilkan oleh siswa. Dengan harapan adanya pemajangan karya siswa memberikan motivasi siswa. Dengan melihat karya siswa yang dipajang akan memberikan 
semangat kepada siswa lain untuk lebih giat belajar sehingga karyanya juga dapat dipajang dikelas dan dapat dilihat oleha teman lain. Harjali (2016:14) mengungkapkan bahwa lingkungan kelas yang mempertimbangkan aspek kenyamanan dan keindahan merupakan syarat penting bagi terciptanya lingkungan belajar yang kondusif. Interaksi guru dan siswa maupun interaksi siswa antar siswa sangat dipengaruhi oleh suasana kelas yang indah dan nyaman. Kenyamanan dan keindahan terdiri atas kenyamanan psikis dan kenyamanan fisik. Kenyamanan psikis adalah kenyamanan kejiwaan (rasa aman, tenang, gembira, dan sebagainya) yang terukur secara subjektif (kualitatif). Kenyamanan fisik dapat terukur secara objektif (kuantitatif); yang meliputi kenyamanan spasial, visual, auditorial dan termal.

Hasil penelitian menunjukkan bahwa dalam mewujudkan pembelajaran aktif beberapa kegiatan guru adalah:

Tabel 2. Strategi guru dalam pemajangan karya siswa

\begin{tabular}{|l|l|}
\hline Kegiatan Guru & \multicolumn{1}{|c|}{ Strategi yang digunakan guru } \\
\hline Pemajangan Karya Siswa & $\begin{array}{l}\text { Memilih karya siswa yang terbaik } \\
\text { untuk dipajangkan }\end{array}$ \\
\cline { 2 - 2 } & $\begin{array}{l}\text { Memilih sudut kelas yang cocok untuk } \\
\text { memajangkan karya siswa. }\end{array}$ \\
\cline { 2 - 2 } & $\begin{array}{l}\text { Memberikan reward kepada siswa } \\
\text { yang menghasilkan karya terbaik }\end{array}$ \\
\hline
\end{tabular}

Pada Tabel 2 tampak berbagai strategi guru dalam pemajangan karya siswa. Strategi ini sebagai bentuk penghargaan kepada siswa atas apa yang telah mereka lakukan. Strategi yang digunakan mulai dari memilih karya siswa yang terbaik untuk dipajangkan, memilih sudut kelas yang cocok untuk memajangkan karya siswa, serta pemberian penghargaan kepada siswa yang meghasilkan karya terbaik. Sejalan dengan pendapat Dadi (2016:257), kelas yang baik memiliki banyak pajangan, terutama pajangan hasil karya siswa dan hanya meliputi apa yang sedang dipelajari siswa. Pajangan yang kurang relevan dengan apa yang sedang dipelajari siswa akan kurang bernilai dan hanya merupakan hiasan dinding belaka. 


\section{KESIMPULAN}

Berdasarkan hasil penelitian dan pembahasan tentang strategi guru dalam pengaturan meja kursi dan pajangan karya siswa untuk mengoptimalkan pembelajaran aktif konsep MIKIR di sekolah dasar dapat dismpulkan sebagai berikut:

1. Penataan meja-kursi siswa yang terlihat menunjukkan bahwa guru mitra guru memiliki kemampuan dalam penataan meja-kursi siswa yang memenuhi kriteria mobilitas, interaksi dan akses (MIA). Hal ini terlihat adanya bentuk penataan meja kursi yang bervariasi. Penataan meja-kursi yang dirancang guru dilakukan berubah-ubah yang disesuaikan dengan bentuk kegiatan pembelajaran. Pengaturan meja-kursi dilakukan secara bekala 1-2 minggu sekali. Bentuk-bentuk pengaturan meja-kursi yang dilakukan oleh guru berbagai macam bentuk baik lingkaran, bentuk U, berpasangan, atau berkelompok yang disesuaikan dengan jumlah kelompok

2. Hasil karya siswa dari proses pembelajaran sudah dipajangkan oleh guru di dinding sisi kelas. Berbagai bentuk karya siswa dibuat dengan memilih karya yang cocok untuk dipajang seperti tulisan siswa (cerita, puisi, laporan), dan hasil pembelajaran yang menunjukkan unsur kreativitas.

Dalam upaya engoptimalkan pembelajaran aktif konsep MIKiR guru tidak hanya terfokus pada unsur-unsur pembelajaran aktif yang harus dilakukan, tapi juga memperhatikan berbagai komponen lain yang mendukung keterlaksanaan pembelajaran aktif diantaranya pengaturan meja kursi serta pemajangan karya siswa. Dengan adanya pengaturan meja kursi yang selalu berubah dan pemajangan karya siswa yang tepat akan membuat siswa lebih termotivasi dalam proses pembelajaran.

\section{DAFTAR PUSTAKA}

Dadi.S. 2016. Peningkatan Kualitas Pembelajaran IPS Melalui Pemanfaatan Model Kelas Di Kelas V Sekolah Dasar Negeri 38 Kota Bengkulu. Jurnal Ilmiah Pendidikan Guru Sekolah Dasar. Vol 9 (2) 2016:255-260

Harjali. 2016. Strategi Guru dalam Membangun Lingkungan Belajar yang Kondusif: Studi Fenomenologi pada Kelas-kelas Sekolah Menengah Pertama di Ponorogo. Jurnal Pendidikan dan Pembelajaran. Vol 23 (1);10-19. 
Isbadrianingtyas, Nafi and Hasanah, Muakibatul and Mudiono, A. (2016). Pengelolaan Kelas dalam Pembelajaran Tematik di Sekolah Dasar. Jurnal Pendidikan: Teori, Penelitian, Dan Pengembangan. Vol 1 (5): 901-904.

Lestari, Y., Rohiat., Anggriani. D. 2017. Pengaruh Penataan Tempat Duduk Terhadap Hasil Belajar Siswa Pada Pembelajaran IPA Kelas V SD N 20 Kota Bengkulu. Jurnal Ilmiah Pendidikan Guru Sekolah Dasar. Vol 10 (1):61-65

Moleong, L,J. 2012. Metodologi Penelitian Kualitatif. Bandung

Novianingsih,H. 2016. Pendekatan Pembelajaran Aktif, Kreatif, Efektif, Dan Menyenangkan Dalam Pembelajaran Matematika Sekolah Dasar. Jurnal Pendidikan Guru Sekolah Dasar, Vol 1 (1):1-11

Zaturrahmi. 2019. Lingkungan Belajar Sebagai Pengelolaan Kelas: Sebuah Kajian Literatur. Ejurnal E-Tech. Vol 7 (6):1-7 